\title{
A survey of energy drink consumption patterns among college students
}

\author{
Brenda M Malinauskas*1, Victor G Aeby², Reginald F Overton ${ }^{3}$, \\ Tracy Carpenter-Aeby ${ }^{4}$ and Kimberly Barber-Heidal ${ }^{1}$
}

Address: ${ }^{1}$ Department of Nutrition and Dietetics, East Carolina University, Greenville, North Carolina, USA, ${ }^{2}$ Department of Health Education and Promotion, East Carolina University, Greenville, North Carolina, USA, ${ }^{3}$ Department of Health, Physical Education, Recreation, and Dance, Virginia State University, Petersburg, Virginia, USA and ${ }^{4}$ School of Social Work, East Carolina University, Greenville, North Carolina, USA

Email: Brenda M Malinauskas* - malinauskasb@ecu.edu; Victor G Aeby - aebyv@ecu.edu; Reginald F Overton - roverton@vsu.edu; Tracy Carpenter-Aeby - carpenteraebyt@ecu.edu; Kimberly Barber-Heidal - heidalk@ecu.edu

* Corresponding author

Published: 31 October 2007

Nutrition Journal 2007, 6:35 doi:10.1/86/1475-289/-6-35
Received: 26 April 2007

Accepted: 3I October 2007

This article is available from: http://www.nutritionj.com/content/6/1/35

(C) 2007 Malinauskas et al; licensee BioMed Central Ltd.

This is an Open Access article distributed under the terms of the Creative Commons Attribution License (http://creativecommons.org/licenses/by/2.0), which permits unrestricted use, distribution, and reproduction in any medium, provided the original work is properly cited.

\begin{abstract}
Background: Energy drink consumption has continued to gain in popularity since the 1997 debut of Red Bull, the current leader in the energy drink market. Although energy drinks are targeted to young adult consumers, there has been little research regarding energy drink consumption patterns among college students in the United States. The purpose of this study was to determine energy drink consumption patterns among college students, prevalence and frequency of energy drink use for six situations, namely for insufficient sleep, to increase energy (in general), while studying, driving long periods of time, drinking with alcohol while partying, and to treat a hangover, and prevalence of adverse side effects and energy drink use dose effects among college energy drink users.

Methods: Based on the responses from a 32 member college student focus group and a field test, a 19 item survey was used to assess energy drink consumption patterns of 496 randomly surveyed college students attending a state university in the Central Atlantic region of the United States.

Results: Fifty one percent of participants $(n=253)$ reported consuming greater than one energy drink each month in an average month for the current semester (defined as energy drink user). The majority of users consumed energy drinks for insufficient sleep (67\%), to increase energy (65\%), and to drink with alcohol while partying (54\%). The majority of users consumed one energy drink to treat most situations although using three or more was a common practice to drink with alcohol while partying (49\%). Weekly jolt and crash episodes were experienced by $29 \%$ of users, $22 \%$ reported ever having headaches, and $19 \%$ heart palpitations from consuming energy drinks. There was a significant dose effect only for jolt and crash episodes.

Conclusion: Using energy drinks is a popular practice among college students for a variety of situations. Although for the majority of situations assessed, users consumed one energy drink with a reported frequency of I - 4 days per month, many users consumed three or more when combining with alcohol while partying. Further, side effects from consuming energy drinks are fairly common, and a significant dose effect was found with jolt and crash episodes. Future research should identify if college students recognize the amounts of caffeine that are present in the wide variety of caffeine-containing products that they are consuming, the amounts of caffeine that they are consuming in various situations, and the physical side effects associated with caffeine consumption.
\end{abstract}




\section{Background}

Energy drink consumption has continued to gain popularity since the 1997 debut of Red Bull, the current leader in the energy drink market [1]. More than 500 new energy drinks were launched worldwide in 2006 and beverage companies are reaping the financial rewards of the 5.7 billion dollar energy drink industry [1]. Energy drinks, including Red Bull, Amp, Monster, Rock Star, Rip It, Full Throttle, and Cocaine, are designed to give the consumer a "jolt" of energy provided by the combination of stimulants and "energy boosters" that they provide, including caffeine, herbal extracts such as guarana, ginseng, and ginkgo biloba, B vitamins, amino acids such as taurine, amino acid derivatives such as carnitine, and sugar derivatives, including glucuronalactone and ribose [1]. Energy drinks typically contain 80 to $141 \mathrm{mg}$ of caffeine per 8 ounces, the equivalent of five ounces of coffee or two 12ounce cans of caffeinated soft drink such as Mountain Dew, Coca Cola, Pepsi Cola or Dr. Pepper [2]. Energy drinks have sugar-containing and sugar-free versions. For example, Monster Energy provides 24 grams of sugar per 8 ounces (12\% sugar concentration) and Rip It A'Tomic Pom provides 33 grams (14\% concentration) [3,4]. Similar to the booming energy drink market, the size of the energy drink container has increased over 300-fold; Monster energy offers consumers a 23 ounces option [3].

Do energy drinks provide the consumer an extra burst of energy as the advertisements would have you believe? Yes, they do. Smit and colleagues found that energy drinks, as compared to placebo, had energizing effects among 18 to 55 year old participants, with effects being strongest 30 to 60 minutes after consumption and sustained at least 90 minutes [5]. Caffeine was found to be the primary constituent responsible for these effects. Although there is no human requirement for caffeine, even low doses of caffeine (12.5 to $100 \mathrm{mg}$ ) improve cognitive performance and mood [6]. However, caffeine has been found to have detrimental health consequences. Riesenhuber and colleagues found that the caffeine (but not taurine) in energy drinks promotes diuresis and natriuresis [7]. Further, acute caffeine consumption reduces insulin sensitivity [8] and increases mean arterial blood pressure [9]. High caffeine consumption is associated with chronic daily headaches, particularly among young women (age $<40$ years) and among those with chronic episodic headaches and of recent onset ( $<2$ years) [10]. Central nervous system, cardiovascular, gastrointestinal, and renal dysfunction have been associated with chronic caffeine ingestion [11]. In sum, the caffeine in energy drinks will provide the consumer the desirable effects of increased alertness, improved memory, and enhanced mood. However, caffeine can have harmful physical consequences.
Although energy drinks are targeted to the 18 to 35 year old consumer [12], there has been little research regarding energy drink consumption patterns among young adults in the United States. The purpose of this study was to determine (1) energy drink consumption patterns among college students, (2) prevalence and frequency of energy drink use for six situations, namely for insufficient sleep, to increase energy (in general), while studying, driving long periods of time, drinking with alcohol while partying, and to treat a hangover, (3) and prevalence of adverse side effects and energy drink use dose effects among college energy drink users.

\section{Methods}

A Registered Dietitian and a Health Educator designed a questionnaire that assessed consumption patterns of energy drinks among college students. We initially interviewed a focus group of 32 college students who were enrolled in a senior-level course. We asked these students open-ended questions regarding situations in which college students use energy drinks, the most common energy drinks college students were using, frequency patterns (average number of energy drinks consumed for each situation the focus group identified and the average number of times per month throughout a semester students use energy drinks for each situation), and side effects from using energy drinks.

Based on the focus group responses we developed a 19item questionnaire. Questions 1 and 2 assessed demographic information (age and sex). Question 3 was a screening question, used to identify energy drink users, and asked "in an average month for the current semester do you drink more than one energy drink per month?" If a participant indicated "no", then they were instructed to skip the remaining questions in the survey and return the questionnaire to the research assistant. Participants who indicated "yes" to Question 3 were instructed to continue the survey, which assessed the type of energy drink usually consumed (regular or sugar-free), side effects associated with energy drink use (jolt and crash episodes, headaches, heart palpitations), and six situations for energy drink use (insufficient sleep, needing more energy (in general), studying for an exam or to complete a major course project, driving a car for a long time, drinking with alcohol while partying, and to treat a hangover).

For the purpose of this study, a jolt and crash episode was in reference to a feeling of increased alertness and energy (the jolt) followed by a sudden drop in energy (the crash) that occurs in response to using energy drinks.

Each of the six situation questions had two follow up questions that assessed the average number of energy drinks consumed for that situation (for example, how 
many energy drinks do you drink at one time following a night of not getting enough sleep?) and the average number of times per month for the current semester the student consumes energy drinks for that situation.

To provide a frame of reference regarding what constituted an energy drink, the introduction of the questionnaire included examples of energy drinks that were popular on the campus and in social establishments in the immediate geographic region when the survey was administered, these included Red Bull, Rock Star, Amp, and Full Throttle. The questionnaire was field tested among 10 randomly chosen students who were in a public location on campus. The questionnaire took approximately two minutes to complete and modifications to the questionnaire were not necessary based on the field test responses.

From mid-November to the first week of December 2006, 11 trained research assistants (undergraduate and graduate college students) recruited students at a single college from public locations across campus to participate in the study. The research assistants first ensured that those they approached were students at the university and that the student had not previously completed the questionnaire.

The institution is a state university, located in the Central Atlantic region of the United States. The fall 2006 enrollment statistics indicate an undergraduate enrollment of approximately 18,000 undergraduate and 6,000 graduate students, $85 \%$ of undergraduates were 18 to 24 years of age, $12 \%$ were 25 to 40 years of age and $3 \% 41$ years of age and older [13]. Further, 92\% of undergraduates attended school full-time whereas the majority (60\%) of graduate students attended part time. In regard to ethnicity of the student body, 76\% were non-Hispanic White, $16 \%$ non-Hispanic Black, 2\% Asian, 2\% Hispanic, 2\% unknown, $<1 \%$ American Indian, and $<1 \%$ non-resident alien.. Sixty two percent of the total student body is female [13].

To diversify our sample, research assistants varied the time of day and days of the week during weekdays to recruit participants. In compliance with the university's Institutional Review Board for Research with Human Subjects (University and Medical Center Institutional Review Board number 06-0718), students were informed of the study protocol and those willing to participate anonymously completed the self-administered questionnaire. The project was carried out in compliance with the Helsinki Declaration.

Analyses were performed using JMP IN ${ }^{\circledast}$ software [14]. Descriptive statistics included means, standard deviations, 95\% confidence intervals, and frequency distributions. Pearson $\chi^{2}$ was used to evaluate differences in frequency distribution of responses. An alpha level of .05 was used for all statistical tests.

\section{Results}

A total of 496 participants, aged $21.5 \pm 3.7$ years (95\% CI $21.3,21.8)$ completed the questionnaire. In regard to the first research question, energy drink consumption patterns among college students, $51 \%$ of participants $(n=$ 253 ) reported drinking greater than one energy drink each month in an average month for the current semester, with significantly more female (53\%) than male (42\%) energy drink users reported, $\chi^{2}(1, N=496)=6.46, p=.01$. Seventy four percent $(n=187)$ of the 253 users drank sugarcontaining versions with significantly more females $(35 \%)$ than males $(12 \%)$ drinking sugar-free versions, $\chi^{2}$ $(1, N=247)=16.56, p<.01$.

Energy drink consumption patterns of college energy drink users for the six situations assessed are reported in Table 1. Insufficient sleep was the most common reason to drink energy drinks, as indicated by $67 \%$ of energy drink users. The majority of users consumed energy drinks to increase their energy (65\%) and to drink with alcohol while partying (54\%). Fifty percent drank while studying or completing a major course project, $45 \%$ while driving a car for a long period of time, and $17 \%$ to treat a hangover. There were no significant differences in use of energy drinks for the six situations assessed by sex, as reported in Table 1.

Table I: Situations of energy drink use among college energy drink users in an average month for the current semester

\begin{tabular}{|c|c|c|c|c|}
\hline Situation & $\%$ of females & $\%$ of males & $\chi^{2}$ & $p(\operatorname{sex})$ \\
\hline Insufficient sleep ${ }^{a}$ & 67 & 68 & 0.17 & .68 \\
\hline Need energy (in general) ${ }^{a}$ & 62 & 69 & 1.27 & .26 \\
\hline Studying or major project ${ }^{\mathrm{b}}$ & 46 & 56 & 2.22 & .14 \\
\hline Driving car for long period of time & 40 & 51 & 3.01 & .08 \\
\hline Mix with alcohol while partyinga & 57 & 50 & 1.33 & .25 \\
\hline Treat hangover ${ }^{\mathrm{a}}$ & 16 & 18 & 0.18 & .67 \\
\hline
\end{tabular}

${ }^{a} n=146$ females, 107 males, $\chi^{2}(I, N=253) ;{ }^{b} n=145$ females, 104 males, $\chi^{2}(I, N=249)$. 
In regard to the second research question, the percent of users drinking one, two, and three or more energy drinks by situation are reported in Table 2 . The majority of energy drink users consumed one to treat a hangover, for insufficient sleep, to increase energy, and while driving a car for a long period of time. Using three or more was a common practice (49\% of users) to drink with alcohol while partying. The percent of users drinking energy drinks $1-4,5-10$, and 11 or more days in an average month for the current semester are also reported in Table 2. For the six situations assessed, the majority of users (73\% to $86 \%)$ consumed energy drinks $1-4$ days in a month.

To further identify relationships between the six situations of energy drink use and energy drink consumption patterns, we summed the number of situations for reported energy drink use and compared this to the maximum number of energy drinks consumed for any of the six situations. These results are reported in Table 3. By sum of situation categories, $16 \%$ to $20 \%$ of energy drink users consumed energy drinks for a total of one to five of the six situations, 7\% consumed energy drinks for a total of all six. As total situations increased so did the maximum energy drink consumption for at least one situation. For example, $40 \%$ to $81 \%$ of energy drink users who reported a total of three or more situations consumed three or more energy drinks for at least one situation, whereas $29 \%$ of those with a total of one situation and $18 \%$ of those with a total of two consumed three or more for at least one situation.

Regarding the third research question, weekly jolt and crash episodes were experienced by $29 \%$ of users, $22 \%$ reported ever having headaches and 19\% heart palpitations from consuming energy drinks, which did not differ significantly by sex, $\chi^{2}(1, N=253)<0.01, p=.97$ for jolt and crash episodes, $\chi^{2}(1, N=234)=0.37, p=.54$ for heart palpitations, $\chi^{2}(1, N=252)=0.45, p=.50$ for headaches. The data for side effects by energy drinks consumed are reported in Table 4. There was a significant dose effect for jolt and crash episodes but not for heart palpitations or headaches. For example, 57\% of energy drink users who reported experiencing weekly jolt and crash episodes also consumed three or more energy drinks for at least one situation, whereas $35 \%$ of those who denied jolt and crash episodes consumed three or more.

\section{Discussion}

Energy drinks are marketed to young adults and marketing efforts may be particularly appealing among college students. For example, Cocaine energy drink, with a Cut Cocaine variety, has been marketed as a "legal alternative" to the class A drug [15]. On April 4, 2007, the Food and Drug Administration issued a warning to Drink Reboot, the firm that markets Cocaine, citing numerous marketing violations, including promoting this product as a street drug alternative [15]. Red Bull energy drink is reportedly a "functional beverage" that was designed to increase physical and mental performance and "is appropriate to drink during sports, while driving, and during leisure activities" [16] whereas Monster energy provides a "double shot of our killer energy brew. It's a wicked mega hit that delivers twice the buzz of a regular energy drink..." [3]. The purpose of this study was to identify energy drink consumption patterns and side effects associated with consumption of energy drinks among college students. We found that energy drink consumption is a popular practice among college students, particularly if the student has had insufficient sleep, if they need more energy in general, while studying for exams or working on major course projects and while driving an automobile for a long period of time.

Improvements in mental functioning are of interest among college students, many who suffer from sleep deprivation. The American College Health Association reported that $71 \%$ of college students whom they surveyed reported insufficient sleep and not feeling rested for at least five of the past seven days [17]. Sleep deprivation

Table 2: \% of college energy drink users ${ }^{\mathrm{a}}$ reporting amount and frequency of energy drink consumption by situation in an average month for the current semester

\begin{tabular}{|c|c|c|c|c|c|c|c|}
\hline \multirow[b]{2}{*}{ Situation } & \multirow[b]{2}{*}{$n$} & \multicolumn{3}{|c|}{ Energy drinks consumed } & \multicolumn{3}{|c|}{ Days per month } \\
\hline & & 1 & 2 & $\geq 3$ & $1-4$ & $5-10$ & $\geq 11$ \\
\hline Insufficient sleep & 169 & 64 & 22 & 14 & 74 & 18 & 8 \\
\hline Need energy (in general) & 165 & 63 & 21 & 16 & 74 & 18 & 8 \\
\hline Studying or major project & 125 & 50 & 36 & 14 & 85 & 10 & 5 \\
\hline Driving car for long period of time & 114 & 63 & 23 & 14 & 86 & 9 & 5 \\
\hline Mix with alcohol while partying & 136 & 27 & 24 & 49 & 73 & 18 & 9 \\
\hline Treat hangover & 42 & 74 & 10 & 16 & 74 & 14 & 12 \\
\hline
\end{tabular}

$a_{n}=253$ college energy drink users. 
Table 3: Maximum number of energy drinks consumed for any of six situations by sum of situations ${ }^{\mathrm{a}}$ in an average month for the current semester among college energy drink users

\begin{tabular}{|c|c|c|c|c|}
\hline \multirow[b]{2}{*}{ Parameter } & \multirow[b]{2}{*}{$n$} & \multicolumn{3}{|c|}{ Maximum energy drink intake for any situation } \\
\hline & & I & 2 & $\geq 3$ \\
\hline$\%$ of I situation responders & 45 & 56 & 15 & 29 \\
\hline$\%$ of 2 situation responders & 38 & 55 & 27 & 18 \\
\hline$\%$ of 3 situation responders & 45 & 33 & 27 & 40 \\
\hline$\%$ of 4 situation responders & 46 & 20 & 37 & 43 \\
\hline$\%$ of 5 situation responders & 43 & 5 & 32 & 63 \\
\hline$\%$ of 6 situation responders & 16 & 6 & 13 & 81 \\
\hline
\end{tabular}

Note: $\chi^{2}(10, N=233)=53.43, p<.01$.

a Sum of six situations reported energy drink use.

is associated with selecting less difficult cognitive tasks and college students who have sleep difficulties report a greater frequency of stress $[18,19]$. Findings from our study support the premise that college students use energy drinks to treat sleep deprivation and while studying for exams or completing major course projects. On the other hand, caffeine consumption has not been found to affect academic performance among college students [20].

The primary ingredient in energy drinks that has a cognitive stimulating effect is the caffeine [5], whereas high sugar content (18\% concentration) does not improve reaction times slowed by sleep deprivation [21]. Further, the combination of caffeine and taurine has no effect on short-term memory [9]. Although low doses of caffeine ( 12.5 to $50 \mathrm{mg}$ ) have been found to improve cognitive performance and mood [6] and $200 \mathrm{mg}$ doses have been found to improve cognitive task speed and accuracy and increase alertness among young adults [22], the amount of caffeine provided in energy drinks can easily far exceed the amount necessary to promote cognitive functioning [23]. This is especially true if a student is consuming 16or 23-ounce cans or multiple cans of energy drinks for a given situation. Although we did not assess the size of the energy drink cans that participants normally consumed, results from our study indicate that in some situations while students are consuming energy drinks, the amount of caffeine that they consume can exceed the amount needed simply to promote cognitive stimulation. For example, $50 \%$ of energy drink users in our study drank two or more energy drinks while studying for an exam or working on a major course project, and $36 \%$ to $37 \%$ drank two or more following insufficient sleep, when they needed energy throughout the day, or while driving an automobile for a long period of time. Further, drinking multiple energy drinks with alcohol was a popular practice among $73 \%$ of energy drink users. The practice of consuming greater amounts of caffeine while socializing has also been documented among American youth [24] and an alcoholic setting is considered by many college students a primary locus to socialize and to meet people [25].

Results from the present study indicate that female and male college students are using energy drinks in a similar fashion. Whereas we found a greater prevalence of energy drink consumption and greater use of sugar-free varieties of energy drink use among females, we identified no situ-

Table 4: Side effects by maximum number of energy drinks consumed for any of six situations in an average month for the current semester among college energy drink users

\begin{tabular}{|c|c|c|c|c|c|c|}
\hline \multicolumn{7}{|c|}{ Maximum energy drink intake } \\
\hline Parameter & $n$ & 1 & 2 & $\geq 3$ & $\chi^{2}$ & $P$ (yes versus no) \\
\hline Weekly jolt and crash episodes & 253 & & & & 19.10 & $<.01$ \\
\hline$\%$ of yes responders & 74 & 12 & 31 & 57 & & \\
\hline$\%$ of no responders & 159 & 40 & 25 & 35 & & \\
\hline Ever having heart palpitations & 215 & & & & 4.77 & .09 \\
\hline$\%$ of yes responders & 40 & 20 & 22 & 58 & & \\
\hline$\%$ of no responders & 175 & 34 & 27 & 39 & & \\
\hline Ever having headaches & 232 & & & & 1.24 & .54 \\
\hline$\%$ of yes responders & 51 & 27 & 24 & 49 & & \\
\hline$\%$ of no responders & $|8|$ & 33 & 27 & 40 & & \\
\hline
\end{tabular}


ation differences nor prevalence of side effects from consuming energy drinks between sexes.

There are a number of limitations to this study that deserve discussion. First, in an effort to ensure the survey instrument could be completed quickly, we collected limited demographic information. Based on the descriptive statistics regarding age, we primarily had undergraduate participants and a slightly greater percentage of male participants as compared to the sex distribution at the university. On the other hand, random sampling throughout the weekdays and times of the day at central locations throughout campus was an advantage to the study design. Additionally, this is a rural state university with a fairly homogenous student body. Second, the data collected was self-reported. In particular, frequency patterns of energy drink intake were asked by situation and were treated as independent and distinct events, which may not have been the case. For example, and energy drink user may consume energy drinks because they had not gotten enough sleep and because they were studying for an exam. As a result, assessment of energy drink consumption may have been overestimated for each of the situation events. On the other hand, the results from this study provide important and novel information regarding energy drink consumption habits among college students. Of particular importance is the finding that using energy drinks for a number of situations is common among college students and that those who use energy drinks for three or more of the situations that we assessed tended to drink three or more energy drinks for at least one situation. Further, side effects of jolt and crash episodes, heart palpitations, and headaches are fairly common, as reported by approximately $25 \%$ of users, and there is a significant dose effect of energy drink consumption and jolt and crash episodes.

\section{Conclusion}

Using energy drinks is a popular practice among college students, as we found that $51 \%$ of 496 college students surveyed reported drinking greater than one energy drink each month. Among college energy drink users, consuming energy drinks is particularly popular for insufficient sleep, when one needs more energy in general, to drink with alcohol while partying, and when studying for an exam or completing a major course project. Drinking three or more for a given situation occurs more frequently among those who consume energy drinks for three or more of the six situations that were assessed. Side effects of consuming energy drinks, including experiencing jolt and crash episodes, hear palpitations, and headaches occur in many energy drink users. However, a dose effect was found only for jolt and crash episodes. Further research should identify if students recognize the amounts of caffeine that are present in the wide variety of caffeine- containing products they consume, the amounts of caffeine that are consumed in various situations, and the physical side effects associated with caffeine consumption.

\section{Competing interests}

The author(s) declare that they have no competing interests.

\section{Authors' contributions}

BMM participated in the study design, performed the statistical analysis, and drafted the manuscript. VGA conceived of the study and drafted the manuscript. AJC assisted with statistical analysis and helped to draft the manuscript. RFO, TCA, and KBH participated in coordination and data collection and helped to draft the manuscript. All authors read and approved the final manuscript.

\section{References}

I. Boyle M, Castillo VD: Monster on the loose. Fortune 2006, I54: I 16-I22.

2. Pronsky ZM: Food Medication Interactions. I0th edition. Edited by: Crowe JP. Pottstown; 1997:274.

3. Monster energy [http://www.monsterenergy.com/product/ energy.php]

4. Rip It energy fuel A'Tomic Pom supplement facts [http:// www.ripitenergy.com/products/atomic pom/]

5. Smit HJ, Cotton JR, Hughes SC, Rogers PJ: Mood and cognitive performance effects of "energy" drink constituents: caffeine, glucose and carbonation. Nutritional Neuroscience 2004, 7:127-139.

6. Smit HJ, Rogers PJ: Effects of low doses of caffeine on cognitive performance, mood and thirst in low and higher caffeine consumers. Psychopharmacology 2000, 152:167-173.

7. Riesenhuber A, Boehm M, Posch M, Aufricht C: Diuretic potential of energy drinks. Amino Acids 2006, $31: 81-83$.

8. Lee SJ, Hudson R, Kilpatrick K, Graham TE, Ross R: Caffeine ingestion is associated with reductions in glucose uptake independent of obesity and Type 2 diabetes before and after exercise training. Diabetes Care 2005, 28:566-572.

9. Bichler A, Swenson A, Harris MA: A combination of caffeine and taurine has not effect on short term memory but induces changes in heart rate and mean arterial blood pressure. Amino Acids 2006, 3 I:47 I-476.

10. Scher Al, Stewart WF, Lipton RB: Caffeine as a risk factor for chronic daily headache: A population-based study. Neurology 2004, 63:2022-2027.

II. Carrillo JA, Benitez J: Clinically significant pharmacokinetic interactions between dietary caffeine and medications. Clin Pharmacokinet 2000, 39:I27-I53.

12. Blue-collar soda? Yeah, we've got that. Consumer Reports 2006:60.

13. Office of Institutional Planning, Research, and Effectiveness, East Carolina University: East Carolina University fact book 20062007. [http://www.ecu.edu/cs-admin/ipre/customcf/factbook/ factbook0607.pdf].

14. Sall J, Creighton L, Lehman A: JMP® Start Statistics Southbank, Australia: Thomson Brooks/Cole; 2005.

15. Cruse AE: Warning letter to drink Reboot regarding firms marketing of the product "Cocaine.". United States Department of Health and Human Services; 2007.

16. What are the effects of Red Bull ${ }^{\circledR}$ energy drinks? [http:// www.redbull.com/\#page=ProductPage.FAQS]

17. American College Health Association: American College Health Association National College Health Assessment Spring 2006 Reference Group Data Report (abridged). Journal of American College Health 2007, 55: 195-206. 
18. Engle-Friedman M, Riela S, Golan R, Ventuneac AM, Davis CM, Jefferson $A D$, Major $D$ : The effect of sleep loss on next day effort. Journal of Sleep Research 2003, I 2: I I3- 124.

19. Dusselier L, Dunn B, Wang Y, Shelley MC II, Whalen DF: Personal, health, academic, and environmental predictors of stress for residence hall students. Journal of American College Health 2005, 54: I5-24.

20. Ratliff-Crain J, Kane J: Predictors for altering caffeine consumption during stress. Addictive Behavior 1995, 20:509-5I6.

21 . The relationship between caffeine consumption and study habits [http://clearinghouse.missouriwestern.edu/manuscripts/ 205.asp]. Missouri Western Clearinghouse

22. Anderson C, Horne JA: A high sugar content, low caffeine drink does not alleviate sleepiness by may worsen it. Human Psychopharmacology: Clinical and Experimental 2006, 21 :299-303.

23. Kohler M, Pavy A, Van Den Heuvel C: The effects of chewing versus caffeine on alertness, cognitive performance and cardiac autonomic activity during sleep deprivation. Journal of Sleep Research 2006, 15:358-368.

24. Bridler L, Remick J, Duffy E: Is caffeine excess part of your differential diagnosis? The Nurse Practitioner 2004, 29:39-44.

25. Pollak CP, Bright $D$ : Caffeine consumption and weekly sleep patterns in US seventh-, eighth-, and ninth-graders. Pediatrics 2007, III:42-46.

26. Strouse JS: College bars as social settings for heterosexual contacts. Journal of Sexual Research 1987, 23:374-382.

\section{Publish with Bio Med Central and every scientist can read your work free of charge}

"BioMed Central will be the most significant development for disseminating the results of biomedical research in our lifetime. "

Sir Paul Nurse, Cancer Research UK

Your research papers will be:

- available free of charge to the entire biomedical community

- peer reviewed and published immediately upon acceptance

- cited in PubMed and archived on PubMed Central

- yours - you keep the copyright

Submit your manuscript here:

http://www.biomedcentral.com/info/publishing_adv.asp 